\title{
Food for Thought Towards Tailored Assays for Cell-Based Approaches to Toxicity Testing
} Gian Paolo Rossini ${ }^{1}$ and Thomas Hartung ${ }^{2}$

${ }^{1}$ Dipartimento di Scienze della Vita, Università di Modena e Reggio Emilia; ${ }^{2}$ Johns Hopkins University, Bloomberg School of Public Health, CAAT, Baltimore, USA and University of Konstanz, CAAT-Europe, Germany

\begin{abstract}
Summary
The call for a new toxicology is mainly a call for cellular approaches and their computational integration. This article reflects on cell models, which are necessary to facilitate the transition. A mechanistic perspective has prompted the characterization of toxicity pathways and toxicity networks in order to develop robust cell-based assays for toxicity testing. Differing use scenarios for cell systems require higher degrees of sophistication, e.g., human-on-a-chip approaches are based on complex organotypic cultures to approximate the repertoire of human physiological reactions and high-throughput tests require simplicity and robustness. The new paradigm emerging under the branding of Toxicology for the $21^{\text {st }}$ Century needs complex models for pathway of toxicity identification and simpler assays for testing the perturbation of any given pathway. With increasing knowledge about underlying mechanisms, the needs for complexity and test specificity will change. Selective cell-based assays are desirable, especially for the detection of novel toxicants and biothreats. Examples from endocrine disruption, pyrogenicity, and especially shellfish toxin testing are used to illustrate such developments.
\end{abstract}

Keywords: toxicity pathways, toxicity networks, mechanistic-based risk assessment, function-specific biomarkers, method validation

\section{Introduction}

The development of alternatives to animal experimentation has received a major boost by the paradigm shift described in the NRC report on Toxicity Testing for the $21^{\text {st }}$ Century: A Vision and a Strategy (NRC, 2007), where cell-based assays are suggested as major tools for risk assessment. The paradigm moves from phenomenological analyses of apical end points of toxicity in animal models to mechanistically-based assays using cells and cell lines. The knowledge obtained from signaling pathways and cellular responses occurring in normal biological systems reacting to endogenous and exogenous signals is capitalized by this paradigm shift. When the duration or strength of perturbations is beyond the self-healing capacity of the homeostatic machinery, the normal pathways become toxicity pathways (TPs), whose perturbations are the basis of consequent adverse effects. It should be noted that this must be distinguished from the chemico-biological interaction leading to the perturbation. It appears that different chemico-biological interactions can result in the same perturbations. In fact, only a limited number of TPs corresponding to the limited number of hazard manifestations might exist. This may indicate that there are only a certain number of meta-stable homeostatic states which are subjected to stress by toxicants; they are considered meta-stable because they typically result in repair (return to original homeostasis) or damage.
A detailed characterization of normal molecular processes and their alterations into TPs, therefore, is expected to clarify relevant mechanism-based perturbations that can be exploited in toxicity testing strategies using cells and cell lines (NRC, 2007). The complexity of signaling pathways and networks currently known (see, for instance, Barabasi and Oltvai, 2004; Papin et al., 2005; Buchanan et al., 2010) is met by a limited knowledge of TPs. In fact, the characterization of TPs and the identification of key perturbations represent the major goals of the first phase of a research program (Lakatos, 1978) to make the paradigm shift a reality (NRC, 2007).

In this paper, we will discuss some issues relevant to the identification and characterization of TPs and consequent perturbations, as well as features of cell-based assays for toxicity testing that capitalize on the knowledge on those pathways. It appears that different assays will be needed to identify TPs and later to test for their perturbation. In particular, we will outline some general molecular scenarios in normal functioning cells where relevant perturbations of physiological processes might ensue when systems become exposed to toxic agents/stressors. We will also examine examples of existing cell-based assays for the characterization of the molecular responses induced by toxic agents as means to clarify the mechanistic basis of their toxicity and their possible detection by specific, cell-based biomolecular assays. These topics will then be examined to discuss features of applicability and scope, including the validation of the cell-based assays. 


\section{A mechanistic frame for toxicity pathways at a cellular level}

The molecular machinery of cells is structured through basic processes bringing about and controlling the functioning of the system, hierarchically organized as depicted by the so-called Central Dogma (Crick, 1958, 1970). Signaling pathways and their perturbed versions (TPs), therefore, are parts of the full machinery, and emphasis on specific sequences of events in experimental studies is often aimed at characterizing elements in the entire systems, either under normal conditions or in molecular toxicology settings (see, for instance, Rossini, 2005; Kholodenko, 2006; Natarajan et al., 2006; Krewski et al., 2011; Rossini et al., 2011). The normal functioning cell, in fact, must be considered as a network of components with relevant interactions between and among subsets of elements (Hartwell et al., 1999; Kholodenko, 2006). In keeping with the complexity of biological systems, the major subsets of molecular processes composing the cellular machinery are outlined in Figure 1. We will use this scheme, from the perspective of toxicity testing, to examine different scenarios of possible perturbations caused by the exposure of cellular systems to toxicants/stressors leading to activation of TPs. This schematic representation must be viewed as an extremely simplified picture with minimal functions outlined and mostly ignoring kinetic and thermodynamic considerations. The scheme, in fact, will be instrumental in outlining the complexity of molecular consequences that may arise from the action of toxic agents on their specific molecular targets in varying scenarios. These considerations will represent our background for further discussion of cell-based assays for toxicity testing.

The scheme of Figure 1 includes DNA replication, transcription, and translation, as well as indications of a few basic functions brought about by cellular proteins, such as the control of transcription by trans-acting transcription factors (TF), intermediary metabolism, and signal transduction. Relevant basal cellular processes, such as ion homeostasis or vesicle trafficking, for instance, have not been inserted in this scheme, as it only represents an oversimplification of minimal functional properties. The proposed scheme, however, encompasses some specific features often encountered in pathways of intermediary metabolism and signal transduction, which will be instrumental in further discussions. The two hypothetical metabolic pathways of Figure 1 , including metabolites $\mathrm{M}_{1-} \mathrm{M}_{8}$ and the enzymes catalyzing individual reactions $\left(\mathrm{E}_{1}-\mathrm{E}_{7}\right)$, for instance, include:

i) a reaction which connects the two pathways so that metabolites $\mathrm{M}_{2}-\mathrm{M}_{4}$ can be products of a distinct series of reactions and have two different precursors $\left(\mathrm{M}_{1}\right.$ and $\left.\mathrm{M}_{5}\right)$;

ii) the end product of one pathway $\left(\mathrm{M}_{4}\right)$ is a modulator of a protein component having a role of effector/transducer $\left(\mathrm{EF}_{\mathrm{y} 2}\right)$ in a signaling pathway;

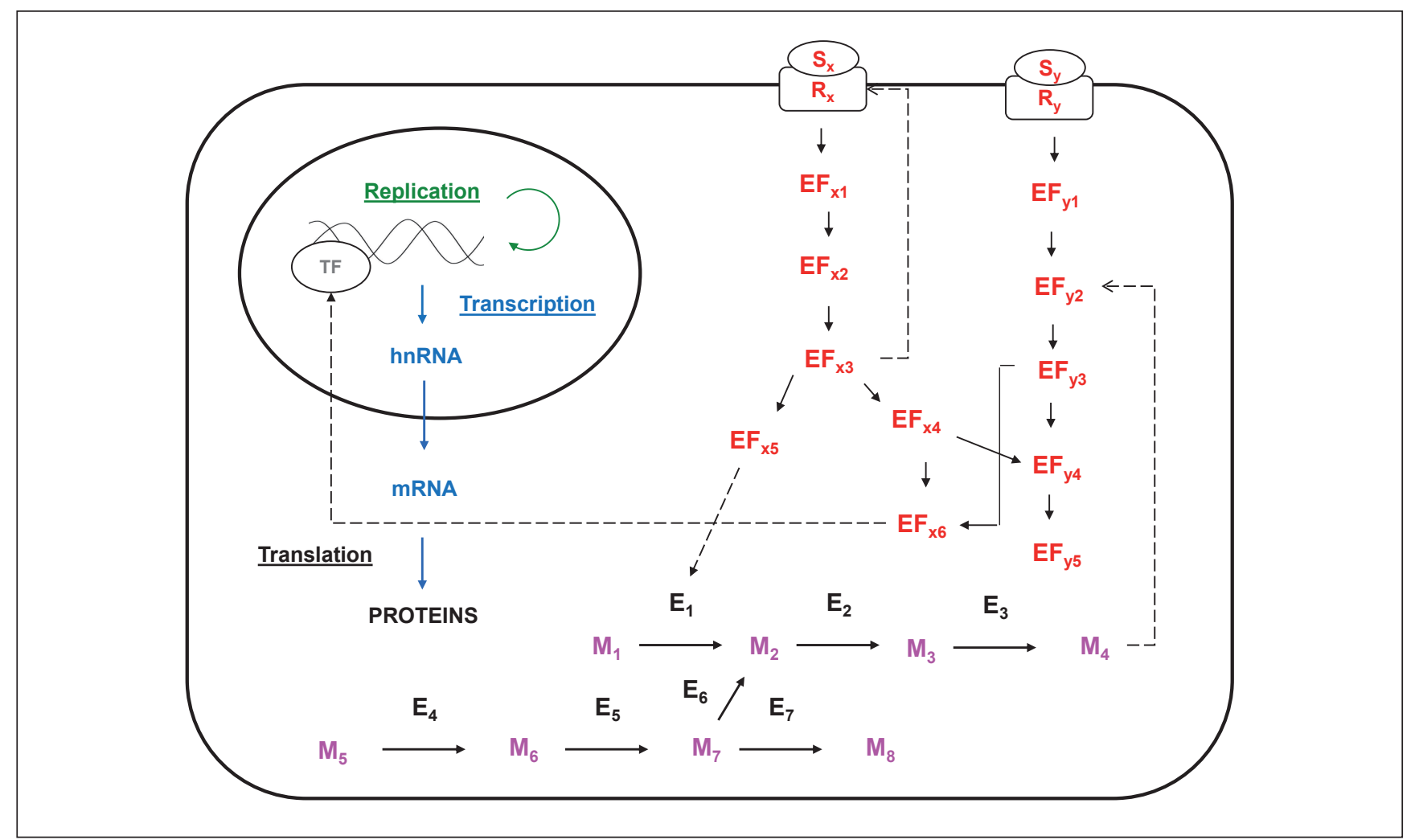

Fig. 1: Schematic representation of basic cellular functions

This simplified model includes major steps of gene replication and expression, as well as hypothetical metabolic and signaling pathways. $T F$, transcription factor; $S_{x}$ and $S_{y}$, chemical signals; $R_{x}$ and $R_{y}$, receptors of chemical signals $S_{x}$ and $S_{y} ; E F_{x 1}-E F_{x 6}$ and $E F_{y 1}-E F_{y 6}$, effectors of the signaling pathways of chemical signals $S_{x}$ and $S_{y} ; E_{1}-E_{7}$, enzymes catalyzing the reactions of metabolic pathways; $M_{1}-M_{8}$, intermediates of metabolic pathways. See text for explanations. 
iii) the enzyme catalyzing the first reaction of one metabolic pathway $\left(E_{1}\right)$ is controlled by the action of an effector $\left(E_{x 5}\right)$ of a signaling pathway.

The two signaling pathways depicted in Figure 1, in turn, include other features found in living systems that are complemented by those already indicated in points $i i$ and iii above, and will be used in our discussions. These include:

i) cross-talks between pathways occurring at different steps;

ii) the functioning of one receptor $\left(\mathrm{R}_{\mathrm{x}}\right)$ is controlled by an effector/transducer $\left(\mathrm{EF}_{\mathrm{x} 3}\right)$ of the signaling pathway triggered by the incoming signal $\left(\mathrm{S}_{\mathrm{x}}\right)$;

iii) an effector/transducer of a signaling pathway $\left(\mathrm{EF}_{\mathrm{x} 6}\right)$ controls the functioning of a transcription factor, thereby modulating the transcription of selected genes.

Toxic agents and stressors may affect a biological system by interfering with proper functioning of one or more processes outlined in Figure 1. Mutagens, for instance, may chemically modify DNA, leading to transcription of RNA, whose altered sequence may be translated into proteins with modified amino acid sequences. If the altered primary structure of the synthesized protein determines a severely perturbed function, and the proliferation of the cell containing the mutated gene continues, the process brought about by the altered protein may be disrupted in the organism. In this scenario, the severity of the adverse effect would depend on the functional role of the normal protein and the specific perturbation caused by the gene mutation. Many examples of this kind of alteration exist in literature, as it is the molecular basis of diseases (including cancer), and results from malfunctioning key components of cell proliferation and the pathways controlling it (see, for instance, King et al., 2002; Weinberg, 2006). Owing to the very extensive literature on mutagenesis and cell-based assays for detecting it (see the recent contribution by Boekelheide and Andersen, 2010), these will not be considered further.

Perturbations leading to TPs can originate at levels of the biological system other than the genome. A toxic effect originates at the level of gene transcription when a toxic agent binds to and perturbs the function of TFs (Fig. 2). In this case, the toxicant causes an altered expression of the genes under the control of the targeted TF, resulting in changes in the cellular levels of the proteins coded by those genes and, hence, an altered performance of functions as compared to that occurring in cells in the absence of the toxic agent. Several possible scenarios exist, including both positive and negative changes in the levels of proteins coded by the genes if transcription is de-regulated. The scenario outlined in Figure 2 includes transcription repression of genes encoding effectors $\left(\mathrm{EF}_{\mathrm{x} 5}\right.$ and $\left.\mathrm{EF}_{\mathrm{y} 5}\right)$ and enzymes $\left(\mathrm{E}_{1}\right.$ and $\left.\mathrm{E}_{2}\right)$, which would lead to impaired functions of those effectors, and to the blockade of one metabolic pathway. The cellular concentrations of metabolite $\mathrm{M}_{4}$ would then depend on conversion of $\mathrm{M}_{7}$ into $\mathrm{M}_{2}$ catalyzed

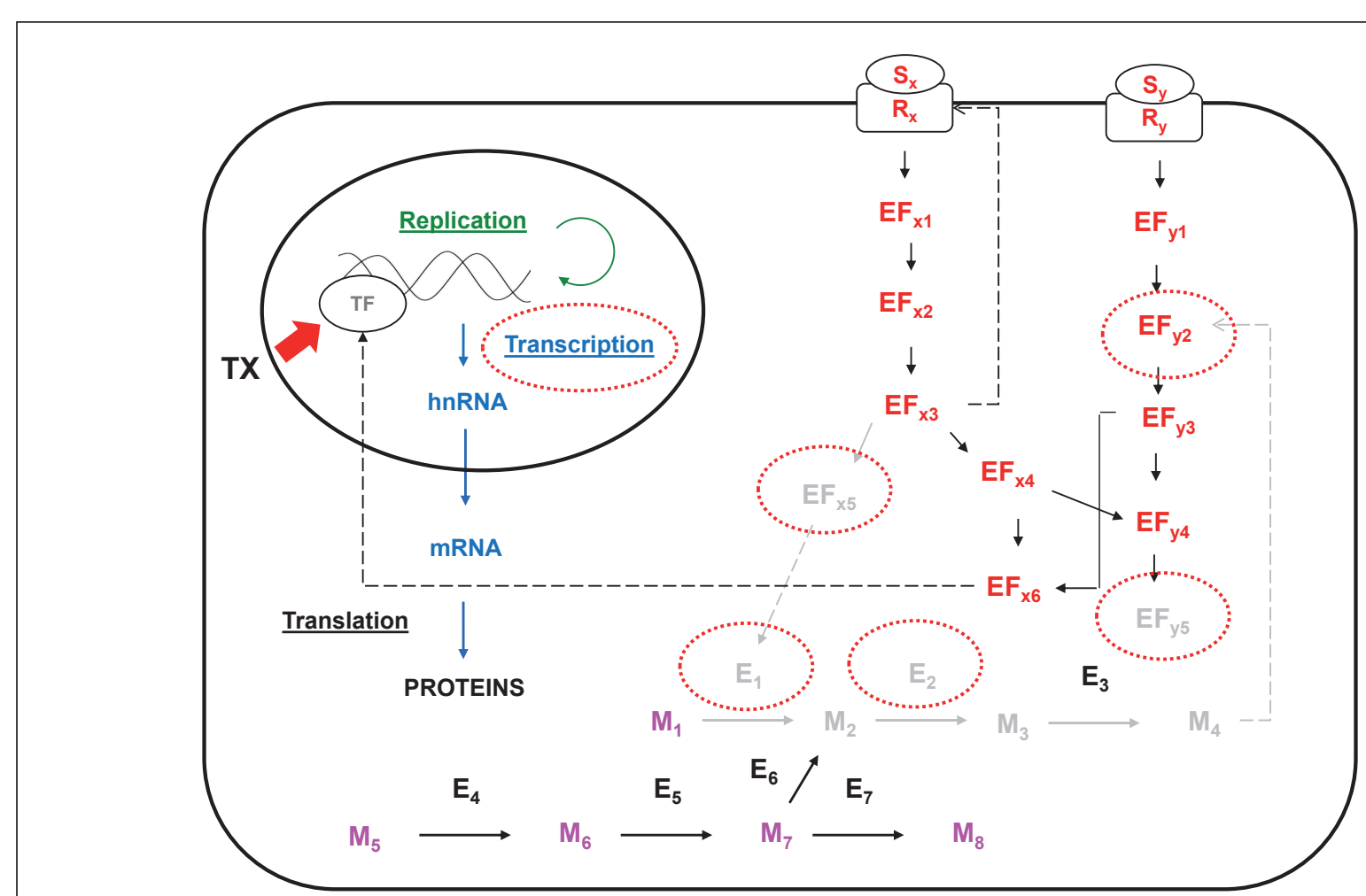

Fig. 2: Alterations in cellular functions induced by a toxicant targeting a transcription factor

The proposed scenario is one of the multiple hypothetical alternatives that can be framed by the scheme reported in Figure 1. TX, toxicant. Other abbreviations are as indicated in the legend to figure 1. The portions of processes altered by the toxicant in this scenario are shown in light gray, and major processes/components involved in this perturbation are circled by a red dotted line. See text for explanations. 
by $\mathrm{E}_{6}$, and the possible decreased levels of $\mathrm{M}_{4}$ resulting from this alternative pathway as a consequence of the toxicant. This could lead to an impairment of the controlling circuitry of the pathway of signal $\mathrm{S}_{\mathrm{y}}$ exerted through the effector $\mathrm{EF}_{\mathrm{y} 2}$ (Fig. 2). Thus alterations exerted at a transcriptional level may have secondary consequences brought about by components participating in distal steps of a TP, whose activity is affected by cross-talks between distinct pathways.

Endocrine disrupters are toxicants interacting with TFs through mechanisms similar to those outlined in Figure 2. Cellbased assays built upon those mechanistic features and used for toxicity testing of compounds to probe endocrine disruption will be considered in the next section.

Many toxicants act on components of signal transduction and other regulatory pathways in biological systems. A possible scenario is depicted in Figure 3, as a background to further discussion about features and consequences of perturbations. The target of a toxicant in Figure 3 is an effector/transducer acting at an early step in a signaling pathway, and the consequence proposed for this event is a blockade of signal transduction controlled by signal $S_{\mathrm{x}}$. Owing to the structure of the proposed pathway, the perturbations caused by this toxicant would not be confined to the functions controlled by signal $S_{\mathrm{x}}$ through its own effectors, but would also include processes regulated by $S_{\mathrm{y}}$ as a consequence of cross-talk between the two signaling pathways exerted by one in- termediate effector $\left(\mathrm{EF}_{\mathrm{x} 4}\right.$ on $\left.\mathrm{EF}_{\mathrm{y} 4}\right)$. The outcome of this alteration in this model would then depend on the exposure of the system to $\mathrm{S}_{\mathrm{y}}$, as cell functioning dependent upon $\mathrm{EF}_{\mathrm{y} 4}$ and $\mathrm{EF}_{\mathrm{y} 5}$ would occur only if signal $S_{\mathrm{y}}$ would turn its signaling pathway on, leading to activation of $\mathrm{EF}_{\mathrm{y} 3}$ (Fig. 3). Similar considerations can be put forward regarding possible effects of the toxicant on gene transcription in this model, as the functioning of TF is postulated to be controlled by $\mathrm{EF}_{\mathrm{x} 6}$. This effector, however, would participate in cross-talks between the two pathways, and malfunctioning in exposed cells could be compensated by the signaling of $S_{y}$ (Fig. 3). Other consequences of cell exposure to the toxicant in this scenario would include the loss of regulatory mechanisms exerted by $\mathrm{EF}_{\mathrm{x} 3}$ on $\mathrm{R}_{\mathrm{x}}$ and a change in the metabolic pathways leading to production of $\mathrm{M}_{4}$, which would be obtained from $\mathrm{M}_{5}$ through the reaction catalyzed by $\mathrm{E}_{6}\left(\mathrm{E}_{1}\right.$ would not be activated by $\mathrm{EF}_{\mathrm{x} 5}$ under these conditions). Within this frame, the regulatory circuitry involving $\mathrm{M}_{4}$ and $\mathrm{EF}_{\mathrm{y}} 4$ would be operative if the cellular concentrations of the modulator $\left(\mathrm{M}_{4}\right)$ in cells exposed to the toxicant were within the physiological range, but would be perturbed if the flow of intermediates in the pathways were inadequate in the presence of inactive $\mathrm{E}_{1}$.

A variety of possible biological systems scenarios can be hypothesized, some of which have been introduced in our models. It should be stressed that the models devised to account for possible perturbations of TPs represent oversimplifications,

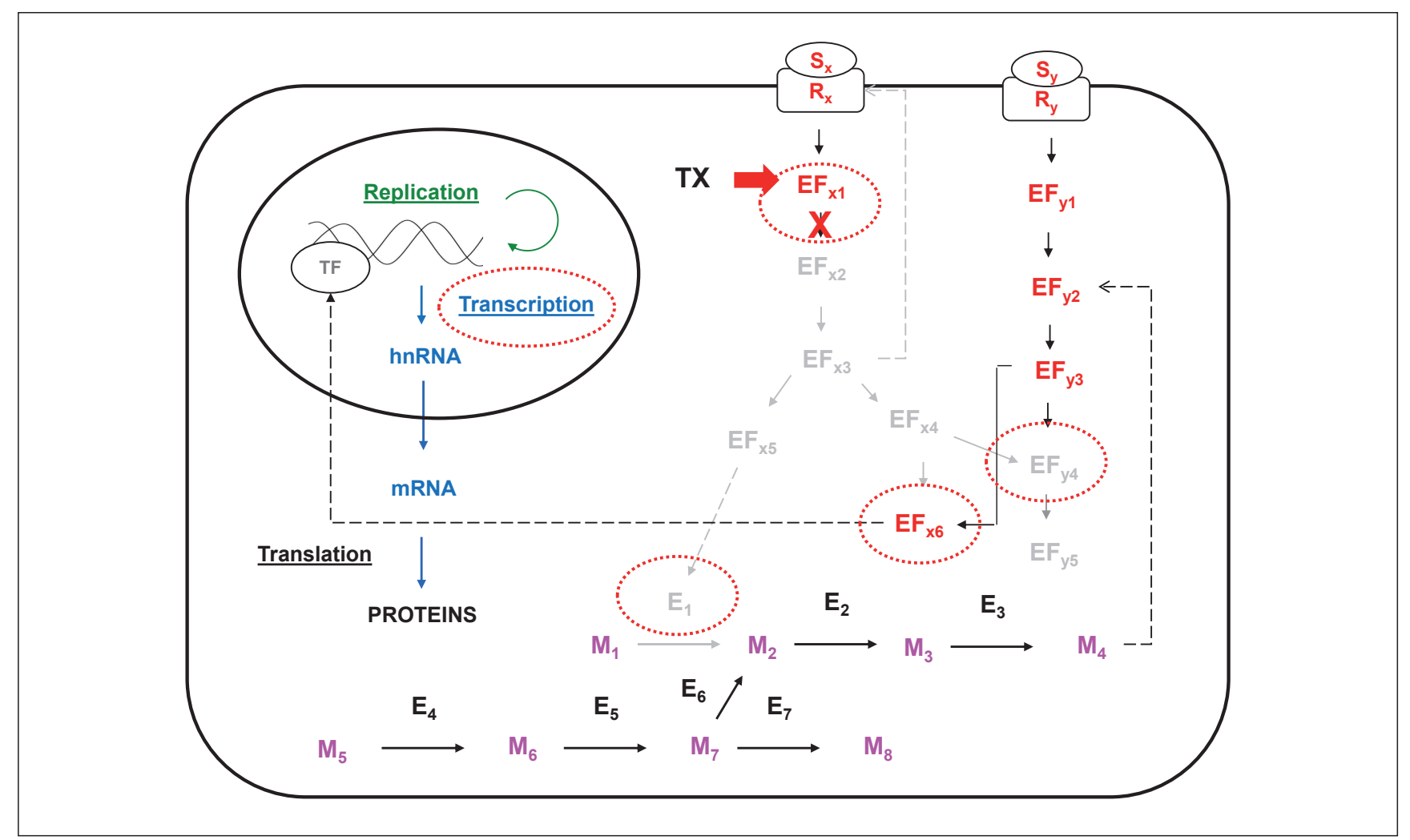

Fig. 3: Alterations in cellular functions induced by a toxicant targeting an effector of a signaling pathway The proposed scenario is one of the multiple hypothetical alternatives that can be framed by the scheme reported in Figure 1. TX, toxicant. Other abbreviations are as indicated in the legend to Figure 1. The portions of processes altered by the toxicant in this scenario are shown in light gray, and major processes/components involved in this perturbation are circled by a red dotted line. See text for explanations. 
which include only some molecular mechanisms of toxins. For instance, the possibility that an agent might directly alter the ultrastructure, and hence the functional properties of a cellular organelle (as is the case for the bee poison melittin which forms channels in the plasma membrane (Bechinger, 1997)), has not been considered in these models, but the mechanistic features and consequences of this type of perturbation can be framed by our reasoning. Similar considerations can be applied to agents directly interacting with enzymes responsible for the metabolism of endogenous physiological modulators, such as organophosphate pesticides acting on acetylcholinesterases (Costa, 2006), which have not been examined in the light of the scheme of Figure 1, but can frame the resulting molecular perturbations. Furthermore, adsorption, distribution, metabolism, and excretion have not been included in our discussion, although toxicokinetics must be taken into account to develop robust risk assessment based on the use of cellular assays.

In general terms, the set of alterations induced by a toxicant in biological systems depends on the structure of the systems themselves. In turn, the severity of alterations, and hence the consequences of system exposure to a toxicant, depends on more quantitative issues, including, but not limited to, the toxicant dose and time of exposure. Considering the scenarios depicted in Figures 2 and 3 , for instance, it is apparent that whether alterations induced by a toxicant may become perturbations transforming normal molecular processes into TPs (and resulting in measurable adverse effects) depends on several factors inherent in the molecular processes altered by the toxicant and on the specific conditions existing in the system and its environment. A detailed knowledge of the molecular players in cellular processes and their regulatory circuitry is needed to identify perturbations which might eventually become responsible for adverse effects in the resulting TP. Thus, the knowledge needed to support the development of robust cell-based assays for toxicity testing should include the characterization of the relevant node(s) of any molecular mechanism of action whose alteration(s) would make a normal pathway a TP. Although the structure of the machinery can be the basis for rational hypotheses, careful experimental analysis of processes and the outcomes resulting from their alterations is mandatory to establish evidence-based alterations which may be robustly associated with specific TPs and adverse effects. Due to the complexity of these networked events, systems approaches modeling these non-linear interactions as a type of virtual experiment will be increasingly necessary (Hartung et al., 2012).

\section{A utilitarian approach to cell models}

Utilitarianism judges the moral worth of an action only by its resulting outcome: "The end justifies the means." In the best of all possible worlds, we would use the test system most closely representing the physiology in question, which would mean - in decreasing order - the relevant human population, a phylogenetically close animal species, an organotypic cell culture, and so on, with many in-between steps. There are many reasons to go down the ladder to the more simple systems (ethics, feasibility, costs, throughput). We might argue that we should use the high- est ranking system affordable for a given purpose because we would expect better results. When restricting ourselves to cellular models, the concept of a "human on a chip" (Hartung and Zurlo, 2012) follows such thinking. However, we have seen that some of the most successful test systems are the simplest, e.g., the Ames test in bacteria (still the most predictive mutagenicity test, Kirkland et al., 2005) or the Limulus Amebocyte Lysate test. What the simple systems lose with regard to physiological resemblance they gain from the higher number of replicates, ease of interpretation of results, and reproducibility (reduction in systematic and random errors). The more components or work steps in a test system, the more things can go wrong and need to be controlled.

The utilitarian approach likely to be most successful is the one that uses the simplest test system that gets the job done. For TP identification, this means that a system that shows a hazard manifestation will allow TP identification (notably, not all TP) if alternative routes can lead to the same phenotype. However, it is likely to be easier to use a number of test systems which together cover all the relevant reference toxicants than trying to find a single test system that almost completely reflects human pathophysiology.

\section{Learning from existing models}

The general considerations of molecular bases of perturbations and their role in TPs outlined above represent the framework for examining examples of cell-based toxicity testing models. The following discussion will consider two major lines of intervention that have been devised to approach different aspects of the same issue. On the one hand, we will consider models developed primarily to assess hazard and the molecular basis of toxicity. Secondly, we will consider cell-based assays for detection and measurement of specific classes of toxic compounds by biomarkers/signatures of selected cellular responses. This approach is not strictly aimed at toxicity testing, but rather extends to many cell-based methodologies capitalizing on the knowledge of molecular mechanisms of action of toxic agents/stressors to perform biological assays of materials suspected to contain those toxic agents/stressors to obtain qualitative/quantitative information regarding the toxicity attributable to that class of agents in those samples.

The cell-based assays for different classes of agents presented in this section are not aimed at providing a full account of the existing literature, but at pinpointing major features and approaches that have been devised in different analytical settings. Furthermore, our discussion will highlight their potential (and possible critical) points with regard to their area of application to support further efforts in the development of cell-based procedures.

\section{Cell-based assays for toxicity testing}

The first approach of cell-based assays for toxicity testing to be considered in this section captalizes on the robust knowledge of the molecular mechanism of action of estrogens, which has been established over the last fifty years. In 1962, with the use of high specific activity tritiated $17 \beta$-estradiol, Elwood V. Jensen's group provided the first firm evidence regarding the existence of recep- 
tors for estrogens in their target tissues (Jensen and Jacobson, 1962), paving the way for the clarification of the molecular mechanism of action of a large superfamily of trans-acting transcription factors and their ligands. Studies in subsequent years have led to firm conclusions about the molecular mechanisms by which estrogens control many aspects of cell functioning and differentiation, including their roles in relevant pathological states such as mammary gland and endometrial cancer (Hewitt et al., 2005; Fuqua, 2009). Briefly, the binding of an estrogenic compound to its receptor in nuclei of target cells leads to a ligand-dependent change in the structure of the receptor protein accompanied by a modification of the binding affinity of estrogen-receptor complex for specific DNA sequences in the nuclear genome (Klein-Hitpass et al., 1988; Mangelsdorf et al., 1995; Biggins and Koh, 2007). The homodimerization of agonist-receptor complexes is then followed by their binding to these DNA sequences termed estrogenresponsive elements (ERE) and this interaction leads to changes in the transcription of selected genes (Fig. 4, left panel). The RNA produced as a consequence of cell exposure to estrogens is used for the synthesis of proteins that bring about the estrogenic response in target cells, as has been established long ago (O'Malley and McGuire, 1968). Although studies in the last twenty years have led to the recognition that the molecular mechanism of estrogenic action can be more complex and would also include nontranscriptional responses (see, for instance, Norman et al., 2004; Wehling and Lösel, 2006), the basic model of estrogen-dependent regulation of gene transcription has not been challenged, and remains the paradigmatic representation of the molecular mechanism controlling gene expression in eukaryotes. In keeping with this view, the clarification of the molecular bases of transcriptional responses to estrogens, and the characterization of the base sequence of the ERE, have been fundamental in the understanding that these molecular steps are key players of estrogenic responses. This general conclusion led to the development of methods for a variety of biological studies, of which detection of estrogen-sensitive processes is just one example. The general structure of cellbased assays using basic features of transcriptional responses in estrogen-responsive systems includes a cell expressing estrogen receptor genetically engineered to include a reporter gene whose transcription is under the control of an ERE, as was the original experimental strategy of Klein-Hitpass et al. (1988). Exposure of these systems to agents possessing estrogenic activity results in enhanced expression of reporter genes, supporting conclusions regarding the estrogenic activity of the agent of interest.

This type of assay has been used for toxicity testing of endocrine disrupters (for recent reviews, see Hotchkiss et al., 2008; Shanle and $\mathrm{Xu}, 2011)$. Some estrogen disrupting chemicals, in fact, can interact with estrogen receptors and cause transcriptional responses induced by estrogens under normal conditions (Naciff and Daston, 2004; Shanle and Xu, 2011). This mechanistic element has been incorporated into the schematic representation of the molecular bases of endocrine disruption shown in Figure 4 (right panel). Multiple structural features, however, determine transcriptional responses involving the estrogen receptor system at the level of ligands, receptor forms, and transcriptional co-factors/activators contributing to changes in the transcription of selected genes (see, for instance, Shiau et al., 1998; McKenna and O'Malley, 2000; Lonard and O'Malley, 2006), including responses to endocrine disrupters (Safe et al., 2002; Shanle and Xu, 2011). These features may be altered either directly or indirectly by endocrine disrupters, which can induce cellular responses by binding to other receptor components acting as transcription factors, such as the aryl hydrocarbon receptor, leading to cross-talk between distinct signaling pathways (Safe and Wormke, 2003; Rüegg et al., 2008). Endocrine disruption would then result from the combined action of a non-physiologic set of proteins synthesized following the expression of a perturbed mRNA pool in affected cells (Fig. 4, right panel).

Although it must be stressed that TPs of endocrine disruption are more complex than the simplified scheme we have outlined, involving additional molecular systems and the contribution of multiple tissues (Hotchkiss et al., 2008; Shanle and $\mathrm{Xu}, 2011$ ), the role of altered transcriptional responses induced by distinct receptor systems and their cross-talk is accepted, providing further support for the use of cell-based assays detecting transcriptional responses of estrogen action. Overall, this is a clear indication that robust information about TPs can be obtained when the molecular mechanisms of normal functions are well characterized, lending further support to the notion that major efforts to characterize the basic molecular machinery of living systems represent the necessary background for the development of mechanistic-based cellular assays conveying reliable information for toxicity testing.

In fact, estrogenic endocrine disruption has been a very active field of in vitro test development in recent years. The state of the art was recently summarized on behalf of the European Commission (Kortenkamp et al., 2011). The report has received quite some criticism (Rhomberg et al., 2012), which we won't discuss, as our concern is the overall relevance of the hazard (Dietrich, 2010). The case shows, however, that specific concerns can be translated to specific assays, i.e., when a mechanism is known, mechanism-based tests can be put forward.

Similarly, other areas where toxicity mechanisms are reasonably well understood are on the brink of substitution by mechanism-based in vitro tests, e.g., skin sensitization (Basketter et al., 2012) and some topical toxicities (Zuang et al., 2008).

\section{Cell-based methods for the detection of toxic agents}

Biological assays using cells and cell lines to detect toxic compounds have received attention in several areas, including that of microalgal toxin-contaminated seafood and pyrogenicity testing. In these areas, instrumental procedures have not been available and/or fully validated for the measurement until recently, a condition which has necessitated extensive use of animal bioassays (mostly mice to test for microalgal toxins in seafood and rabbits for microbial contaminants). Past EC legislation required the use of mouse bioassays for the detection of some lipophilic toxins in contaminated shellfish to protect consumer health (EU, 2005). The lack of specificity of these bioassays and the ethical concerns linked with the extensive use of animals for analytical purposes have been the major driver for the development of cell-based assays (Rossini, 2005; Hess et al., 2006; Schindler et al., 2006, 2009). The pyrogen test in rabbits, in place for more than 40 years, was largely replaced by a test with correlative 
but not mechanistic similarity. The observation that horseshoe crabs react to bacteria with a clotting reaction was translated into an assay for endotoxin, though it misses pyrogens from Grampositive bacteria, fungi, etc. and does not represent the potency of different endotoxins in humans. These and some other problems, such as untestable products and false-positive reactions, were only overcome by the creation of assays based on the human mechanism of fever induction. The immune recognition of Gram-negative endotoxin has been largely elucidated, with the blood monocyte identified as the major sensing cell and cytokines such as interleukin- $1 \beta$ identified as key messenger molecule. The discoverer of this mechanism and, in particular, of the relevant receptors, received the Nobel Prize 2011. The respective microbial counterpart and its human receptor are still not known, though evidence is increasing (Rockel and Hartung, 2012). This shows that where a mechanism is not completely known, the use of human primary cells in a physiologic/organotypic environment is the best approximation of a functional assay.

With regard to microalgal toxins in shellfish, although regulatory recognition of instrumental methods for lipophilic toxin detection in contaminated materials has been recently intro- duced in the EU (EU, 2011), efforts aimed at the development of cell-based methods has continued, as they are considered of higher value for some purposes. Efforts in this area are supported by the recognition that naturally contaminated materials often include many distinct analogues (MacKenzie et al., 2002; Aasen et al., 2005; Dell'Aversano et al., 2008; Rehmann et al., 2008) of varying potency, pinpointing the need to quantify the full series of compounds with toxicological relevance. A second line of intervention recognizes that contamination of seafood by microalgal toxins has been evolving over the years, and novel or atypical contaminations have been detected (Moore and Scheuer, 1971; Hu et al., 1995; Deeds and Schwartz, 2010; Ledreux et al., 2012). Thus, cell-based assays, which have the potential to detect toxicologically relevant components of both characterized toxins and novel agents, have been sought. Some approaches to the development of these assays will be considered in this section, with a focus on seafood contaminated by microalgal toxins, which provides interesting case studies.

First attempts to develop cell-based assays for biotoxins contaminating shellfish included the analysis of morphological features of cells exposed to toxins (Aune, 1989; Amzil et al., 1992).

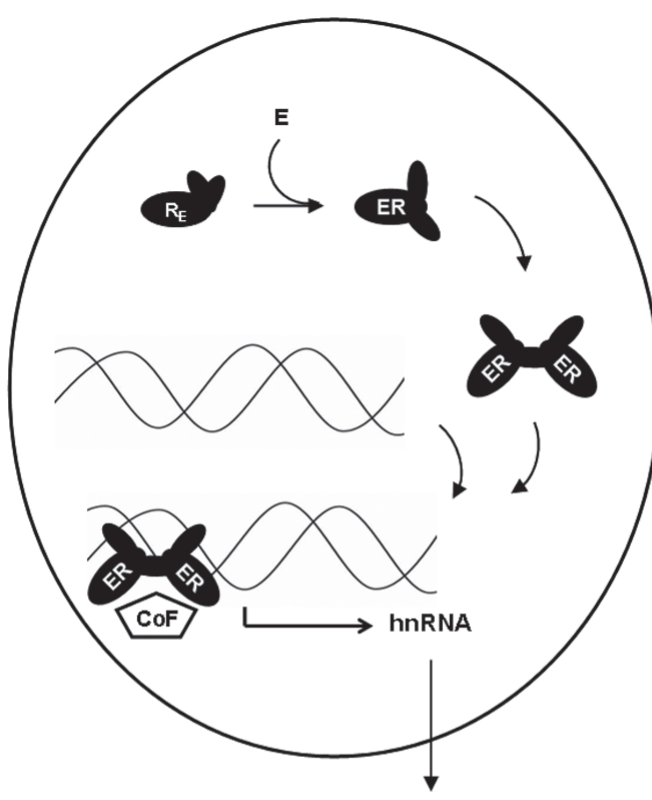

Physiologic mRNA pool

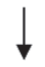

Physiologic Protein Set

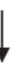

ESTROGENIC RESPONSE

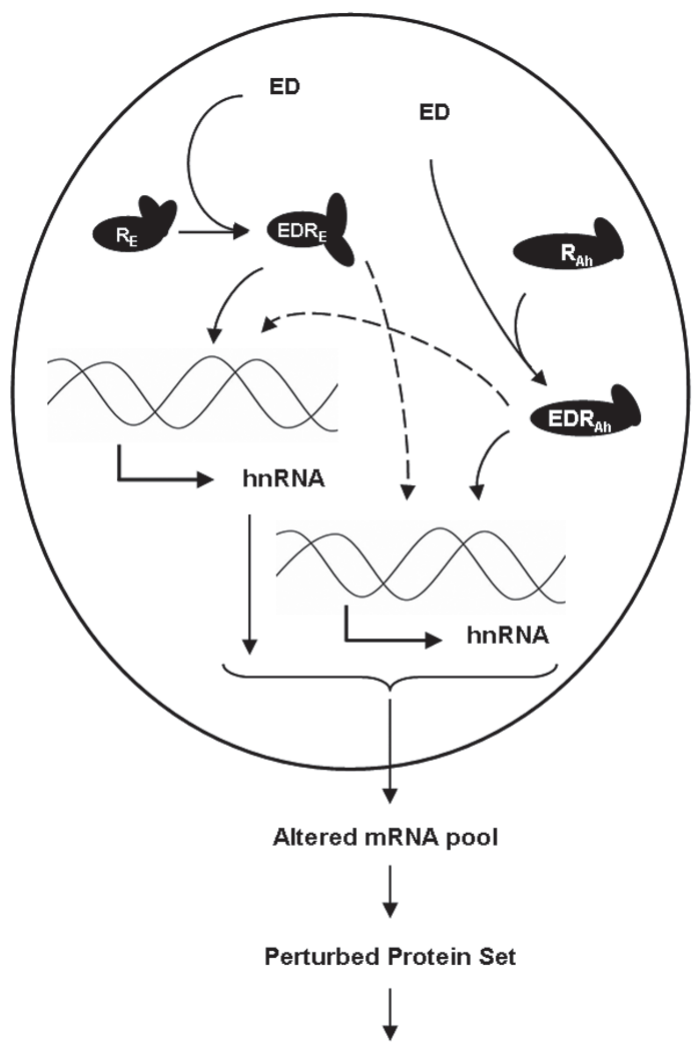

ENDOCRINE DISRUPTION

Fig. 4: Schematic representation of transcriptional mechanisms of estrogenic responses (left panel) and their alteration by endocrine disrupters (right panel)

$E$, natural estrogen; ED, endocrine disrupter; $R_{E}$, estrogen receptor; $R_{A h}$, aryl hydrocarbon receptor; ER, estrogen-receptor complex; EDRE, endocrine disrupter-estrogen receptor complex; EDRAh, endocrine disrupter-aryl hydrocarbon receptor complex; $\mathrm{CoF}$, transcriptional co-factor. The dashed lines indicate possible cross-talk between signaling pathways of different receptors. See text for details. 
The significant degree of subjectivity inherent into analysis of cell morphology and the non-specificity of cytotoxicity assays have eventually led to efforts aimed at developing procedures based on the analysis of responses that could be mechanistically linked to a toxin and would then represent a toxin-specific readout.

The prototype of mechanistic-based cellular assays for the detection of toxins was developed in 1988 (Kogure et al., 1988). It was devised to detect toxins blocking voltage-gated sodium channels $(\mathrm{NaV})$, such as tetrodotoxin, as well as saxitoxingroup compounds (STX), which are responsible for paralytic shellfish poisoning (Rossini and Hess, 2010). These compounds are known to bind to site 1 of the $\alpha$-subunit of $\mathrm{NaV}$, blocking the entrance of the ion into the cell (Castèle and Catterall, 2000; Rossini and Hess, 2010). The loss of sodium conductance in excitable cells, as a consequence of their exposure to STX, prevents membrane depolarization and the transmission of the action potential, leading to impairment of neuromuscular function in the organism (Rossini and Hess, 2010). The cell-based method developed to detect STX capitalized the knowledge of its molecular mechanism of action in excitable cells and exploited a neuronal cell line, which then gave its name to the procedure - the neuroblastoma assay (Kogure et al., 1988; Gallacher and Birkbeck, 1992; Jellett et al., 1992; Manger et al., 1993). In this assay, cells are exposed to veratridine, leading to opening of $\mathrm{NaV}$, and to ouabain, blocking $\mathrm{Na}^{+}, \mathrm{K}^{+}$-ATPase and the extrusion of sodium from the cells, causing the impairment of ion homeostasis in neuroblastoma cells resulting in cell death (Fig. 5). If veratridine/ouabain-treated cells are exposed to STX, the toxin blocks $\mathrm{NaV}$ and sodium entrance, preventing sodium accumulation into neuroblastoma cells and allowing their survival. The knowledge of the mechanism of action of STX and of cellular physiology, as well as the use of pharmacological tools targeting specific cellular components and processes, has thus allowed for a clever arrangement of agents, leading to responses of undeniable specificity in the stimulus determining the life or death fate of neuroblastoma cells. This mechanistic approach provides a readout of cell responses which is informative in both qualitative and quantitative terms. Cell survival, in fact, depends on the presence of STX in the materials challenging the cells, and quantitative estimates of the total content of toxin (in equivalents) can be obtained by interpolating data in a dose-response curve of the assay, using an appropriate standard toxin (Kogure et al., 1988; Gallacher and Birkbeck, 1992; Jellett et al., 1992; Manger et al., 1993).

If the general features of the neuroblastoma assay are put into perspective, it can be argued that the response is functionspecific rather than toxin-specific. In fact, the assay can detect chemically distinct compounds, such as tetrodotoxin and STX, which share the property to bind site 1 of $\mathrm{NaV}$ and block sodium conductance (Kogure et al., 1988). The neuroblastoma assay, therefore, illustrates two important aspects of cell-based assays to detect toxic agents/stressors. The first refers to the specificity of a cell-based assay, which is determined by the mechanistic constraints imposed on the system by the structure of the assay itself. In the case of the neuroblastoma assay, a pretreatment of cells with veratridine and ouabain confines cell readouts to effects resulting from the impairment of $\mathrm{Na}$ homeostasis in the cellular system. The second point is that cell-based assays are function-related. Other compounds sharing the molecular mechanism of action of STX, such as tetrodotoxin, can induce the same results in the neuroblastoma assay. These features are not confined to the neuroblastoma assay, however, and are shared by cell-based methods in broader terms, as will be further discussed in the following examples. Whether these features might represent a limitation or an advantage essentially depends on the purpose of any assay. In fact, the depth and breadth of the

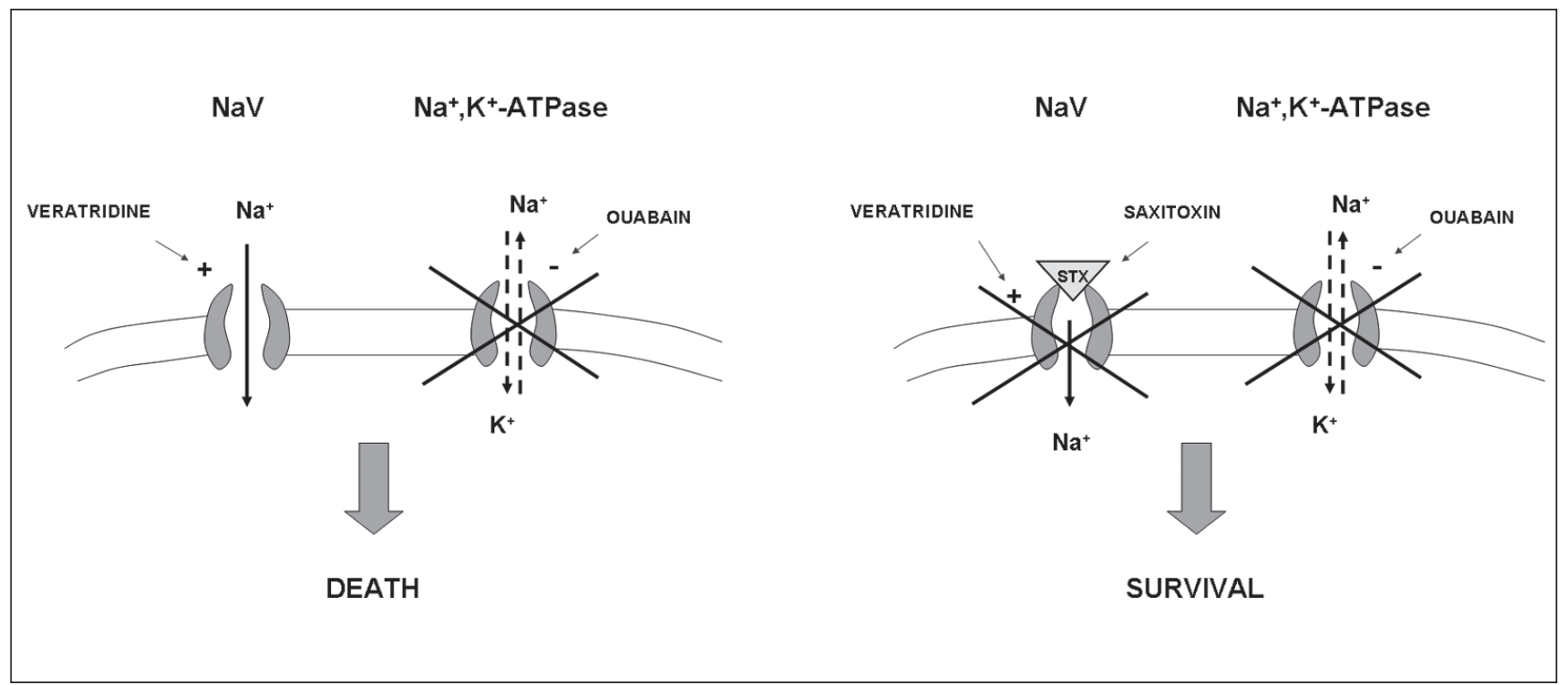

Fig. 5: General structure of the neuroblastoma assay for saxitoxin-group toxins

In the absence of saxitoxin (STX), veratridine/ouabain treatment induces a collapse of $\mathrm{Na}^{+}$homeostasis, resulting in cell death (left panel). If veratridine/ouabain-treated cells are exposed to saxitoxin, it associates with voltage-gated sodium channels ( $\mathrm{NaV}$ ) and blocks $\mathrm{Na}^{+}$entrance into the cells, preventing cell death and allowing cell survival (right panel). See text for details. 
knowledge available on the molecular mechanism of action of selected agents/stressors determines the potential of individual cell-based procedures.

Some interesting features of these concepts can be illustrated by another example of a cell-based assay for detection of yessotoxins (YTX), another class of natural products from microalgae. The human toxicity of this class of compounds by oral exposure is debated (EFSA, 2008) and some analogues of the group have been regulated by the EU (EU, 2004). At the beginning of this century, YTX-group compounds were classified among the diarrhetic shellfish poisoning (DSP) complex and were regulated as such (EC, 1991), without distinguishing the different chemical classes of lipophilic toxins, including dinophysistoxins (DTX), YTX, pectenotoxins (PTX), and azaspiracids (AZA). Knowledge accumulated about these different substances, creating distinctions with regard to chemical properties and toxicity and leading to distinct limits for the different classes of compounds (EC, 2002). The analytical tools for the detection of those groups of compounds in shellfish, however, were not fully developed, posing serious difficulties for monitoring contaminations and risk management. Past EU legislation required the mouse bioassay for the detection of different classes of lipophilic toxins. Since this represented an unspecific tool, it provided a strong drive for the development of alternatives for the specific detection of toxins belonging to different chemical groups (Rossini, 2005; Hess et al., 2006). One such alternative was devised as a consequence of a serendipitous observation. In the course of studies on the molecular responses induced by okadaic acid (OA), it was discovered that the reference compound of the DTX group and YTX affected the cell-cell adhesion molecule E-cadherin in different ways in an epithelial cell line. Cell exposure to OA, in fact, led to an overall loss of cellular protein with a concomitant relative accumulation of the $135 \mathrm{kDa}$ E-cadherin precursor, whereas YTX induced a prominent increase in the cellular content of a $100 \mathrm{kDa}$ E-cadherin fragment. The toxin-selective effects were dose-related, and a cell-based method for the detection of the two classes of compounds was developed (Patent Application, 2002). The characterization of the procedure for the detection of YTX in naturally contaminated samples was then carried out (Pierotti et al., 2003). High doses of a PTX analogue (PTX-6) were not found to alter the E-cadherin molecule in the same model system, leading to the conclusion that the cell-based effect could be considered YTX-selective and used for the detection and measurement of this class of compound in shellfish material (Callegari et al., 2004),

The initial inclusion of AZA-group compounds among the socalled DSP complex of lipophilic toxins, however, led to further studies on this assay because the procedure used for the preparation of samples to be subjected to analysis could also lead to extraction of AZAs (in case this contamination was present in the samples). Subsequent investigations were then carried out into the molecular responses induced by AZA-1 - the reference compound of AZA-group toxins - and showed that the accumulation of the $100 \mathrm{kDa}$ E-cadherin fragment could also be induced by AZA-1 in that model system (Ronzitti et al., 2007). Thus, the molecular marker used to detect YTX by a cell-based assay was not specific, nor was the proposed procedure.
The implications of those findings have supported further studies on the molecular mechanisms of action of YTX and AZA-groups of compounds, leading to the conclusion that the accumulation of the $100 \mathrm{kDa}$ E-cadherin fragment is caused by inhibition of endocytosis (Callegari, and Rossini, 2008; Bellocci et al., 2010). These specific issues will not be discussed further here; instead we will confine our attention to some heuristic indications provided by those findings that are relevant for the framework of cell-based methods for the detection of toxic agents/stressors.

The two cell-based assays for the detection of microalgal toxins reported above exemplify the different potential of readouts with regard to the specific recognition of chemicals, depending on the degree of knowledge of molecular processes involved in the response to individual agents and their TPs. The major molecular features of neuronal transmission and the role played by sodium ions in this process are known at a depth which can support the development of a cellular assay fit for the purpose of detecting components perturbing one of the effectors of the response. The full TP of the agent, in this case, could be represented by a scheme similar to that reported in Figure 3, where receptor and effectors/transducers could be mostly defined in molecular terms. In the case of the E-cadherin assay, the incomplete knowledge about the molecular mechanism of action of YTX and AZA would provide only a partial account of a process (Rossini and Hess, 2010). In this case, the scheme could be structured as in Figure 3, but the lack of knowledge of receptors and relevant effectors would hamper a detailed description of their full TPs. The recognition that the detection of the 100 $\mathrm{kDa}$ E-cadherin fragment occurs when endocytosis is blocked, however, can be exploited in analytical settings. The accumulation of the $100 \mathrm{kDa}$ E-cadherin fragment in epithelial cells, in fact, could become a molecular biomarker of response for agents blocking protein degradation through endocytosis and lysosomal disposal, representing a function-specific, rather than a toxin-specific, molecular biomarker.

Overall, the detection of toxic compounds by the use of cells and cell lines implies a specificity issue which must be taken into account whenever considering the development of procedures. The readout used to detect the response of the cellular system to the agent in question, therefore, should be linked to its inducer by cause-effect relationships, and appropriate knowledge of the molecular mechanism of action of the agents to be detected is needed.

\section{Looking for new robust models}

The full elucidation of TPs and the identification of their rate limiting points represent two pre-requisites for the development of robust assays for the evaluation of perturbations of toxicity testing (NRC, 2007). Biomarkers are to be found among the components of the normal pathways participating in rate limiting processes affected by toxicants. Biomarkers, therefore, would represent the molecular components whose altered biological activity indicate malfunctioning of the system and consequent adverse effects due to abnormal cellular levels and/or modified structural features. 
The qualification of a cell-based assay, then, depends on the robustness of the biomarker, with reference to its potential for reporting the conversion of a normal pathway into a TP.

In the examples provided in the previous section, the responses detected by cell assays could be viewed as biomarkers of altered functioning within a TP whenever appropriate knowledge of key steps of the normal pathway had been established. The detection of a transcriptional response under the control of an ERE and the perturbation of $\mathrm{Na}^{+}$homeostasis, in fact, would not provide uncertainties about their functional consequences in biological systems. Still, endocrine disruption is recognized to include perturbation of endocrine systems in addition to the estrogen receptor (Shanle and $\mathrm{Xu}, 2011$ ), highlighting the importance of an integrated approach in the characterization of normal pathways and TPs. In other words, the presence of known physiological mechanisms increases the likelihood of the presence of others that are not yet identified.

The importance of cell-based assays, with features supporting firm conclusions of specific toxic effects of tested substances based on mechanistic considerations, is obvious. It seems appropriate, however, to stress that the scope of such assays can be much wider. Whenever molecular biomarkers of a toxic effect are identified and exploited in a robust cell-based assay, the procedure can become a tool for testing whether an unknown sample could effectively contain agents with that identifiable toxic activity. Both the environment and humans might become unpredictably exposed to new, or else undetermined, toxic substances, and getting prompt insight into the toxicological potential of those agents may be of great societal relevance. Two areas of exploitation of functional cell-based assays would include protection from bioterrorism and the detection of new toxic substances in the environment.

Existing scenarios indicate that these possibilities may not be confined to fiction, and we will limit this discussion to some recent examples of natural substances whose features might have a wider applicability.

Blooms of microalgae of the genus Ostreopsis have been recorded with increasing frequency and geographical expansion in waters of temperate countries in the last twenty years (Galitelli et al., 2005; Penna et al., 2005; Aligizaki and Nikolaidis, 2006; Tichadou et al., 2010). Ostreopsis algae are known to produce toxins classifiable among the palytoxin-group (Usami et al., 1995; Ciminiello et al., 2006). This group includes large polyether molecules which are recognized to bind to $\mathrm{Na}^{+}, \mathrm{K}^{+}$ATPase and convert the ion-specific pump into a non-specific cation channel (reviewed in Rossini and Bigiani, 2011). The toxic potential of palytoxin-group substances in humans is still being discussed (EFSA, 2009; Tubaro et al., 2011), but concerns were raised in 2005 when approximately 200 people were admitted to hospitals in Genoa, Italy with symptoms involving primarily the respiratory tract after being at the coast in areas where blooms of O. ovata were taking place (Durando et al., 2007). Similar cases have been recorded in other Mediterranean countries (Aligizaki et al., 2008, 2011), but formal proof of causeeffect relationships between the Ostreopsis blooms and human illnesses is still lacking. Cell-based assays are available for the detection of palytoxin-group toxins (reviewed in Riobó and
Franco, 2011) that incorporate different mechanistic constraints for their specificity, such as the use of toxin-specific antibodies, an inhibitor of $\mathrm{Na}^{+}, \mathrm{K}^{+}$-ATPase (ouabain), and the structuring of the procedure aimed at detection of palytoxin-induced cytolysis (Bignami, 1993; Bellocci et al., 2008, 2011; Cañete and Diogène, 2008; Riobó et al., 2008). The insufficient knowledge of the actual toxicity of these substances in humans under different exposure conditions, however, as well as the incomplete characterization of the molecular modes of action of palytoxin-group toxins and the relative potency of the analogues of the group, have hindered the exploitation of molecular biomarkers and cellbased assays to provide robust quantitative estimates regarting the toxicity of suspected materials. Existing cell-based assays, in fact, can be exploited to detect and quantify palytoxin-group toxins, but may not, at the moment, provide robust information about toxicity in humans and other organisms.

A second case refers to unexplained toxicity detected in some shellfish samples from the Arcachon Bay, France since 2005 (Butler, 2006; Ledreux et al., 2012). The issue was raised when the testing of shellfish extracts in the mouse bioassay gave positive results, i.e., mouse death within 24 hours of extract administration, but none of the already characterized classes of toxins was detected in those extracts, indicating that those materials most likely contained substances of atypical toxicity (Ledreux et al., 2012).

In the two cases mentioned above, the availability of cellbased assays which could firmly link detection of selected biomarkers to some recognized functional alteration would have provided significant information about toxicological features of not-yet-known/suspected toxicants. The incomplete information available regarding the human toxicity of palytoxin-group toxins (EFSA, 2009), and the use of a cytotoxicity assay devoid of mechanistic-based constraints (Ledreux et al., 2012), however, represent severe obstacles to the use of those cell-based methods for toxin detection. In more general terms, the availability of cell-based assays for the detection of function-specific responses/ perturbations would allow evidence-based predictions of defined toxicities of samples suspected to contain hazardous compounds independent of their state with regard to already established properties or yet-to-be-recognized toxicants. Thus, cell-based assays detecting function-specific perturbations would allow transition from toxin-specific markers for the detection of something we already know about toward function-related markers for the detection of something we do not know about (but might be hazardous). By the same token, cell-based assays for the detection of function-specific responses/perturbations would provide toxicological information about materials regardless/independent of their chemical characterization, and would represent valuable tools for the protection of human health and the environment from unpredictable toxicants and biothreats, as well as the discovery of new biologically active chemicals.

\section{Cell-based assays tailored for specific needs}

Robust predictions about the toxic potential of agents tested by cellular systems strictly depend on the principle that mechanis- 
tically defined perturbations induced in vitro match recognized adverse effects and responses at an organismal level. This general consideration relies on two major premises: the identification of function-specific responses and the validation of cell-based assays suitable for the detection of those responses. The complexity of cellular functioning and the mechanisms responsible for its control in different tissues and conditions are at the basis of the contention that a one-size-fits-all procedure will not be a solution, but suites of cell-based assays are expected to provide proper tools for toxicity testing (NRC, 2007). In line with this view, the NRC report emphasizes the importance of harnessing the technological tools developed in the post-genomic era. This would include system-level analyses and high-throughput technologies (see, for instance, Naciff and Daston, 2004; Inglese et al., 2006; Lettieri, 2006; Judson et al., 2008; van Vliet, 2011), which are being extensively discussed with regard to toxicity testing (Boverhof and Zacharewski, 2006; Collins et al., 2008; Hartung, 2009; Krewski et al., 2011; Hartung and McBride, 2011; Rossini et al., 2011). We will not review the existing literature on these tools here, but will pinpoint two issues stemming from the mechanistic frame discussed above and other available information, the consideration of which could support efforts aimed at the development of suites of cell-based assays for toxicity testing.

The first issue stems from the pervasive use of system level analyses to obtain accounts of responses of cellular systems to perturbing agents, including toxicants. The information about bona fide entire molecular domains obtained by "omics" approaches, such as the cellular pools of expressed mRNAs, synthesized proteins, or metabolites, certainly provide snapshots of cellular components in defined conditions, whose mechanistic relationships are probed by different tools and extensive use of bioinformatics. The emerging pictures then exploit the knowledge already obtained by more classical reductionist approaches, whereby cause-effect relationships have been established using simpler molecular systems. Thus, using databases to identify mechanistic relationships in terms of ontologies strictly relies on the collection of past and ongoing studies into elements of the system as well as the classification of their properties according to defined criteria (such as subcellular location, physical interactions, etc.). The integration between the holistic approach of system level analyses and of reductionist investigations to refine mechanistic information regarding relevant components of the system at a cellular level could then support more effective characterization of functional responses (Rossini et al., 2011) and the development of tailored cell-based assays for toxicity testing.

The importance of system level analyses for the characterization of cellular processes poses a second issue readily apparent upon consideration of the general organization of cellular systems at a molecular level (as outlined in Fig. 1). Even though we assume a significant degree of simplification, cellular systems still comprise different molecular domains (genome, transcriptome, proteome, metabolome) structured over time and space, with extensive interactions between and among components, pathways, and processes at different levels of biological complexity. Cross-talk between signaling pathways, for instance, would pertain primarily to molecular mechanisms controlling cellular functioning, whereas converging/diverging metabolic reactions often represent the basic processes of cellular systems and housekeeping functions. These few examples provide only a very limited account of the full range of interacting sub-systems existing at a cellular level, whose overall structure encompasses a hierarchical organization as captured by the Central Dogma and the flow of information from nucleic acids to proteins (Crick, 1958, 1970).

Mechanistic descriptions of cellular processes and their perturbations should take into account this complexity (Buchanan et al., 2010). Cell-based assays developed for toxicity testing and other areas should capture the complexity underlying selected processes and convey the relevant biological information into readouts to account for the mechanistic bases of their occurrence, thereby embodying the specificity of a recognizable functional perturbation. The development of procedures tailored to detect specific functional alterations will be a driver for the establishment of effective suites of cell-based assays for toxicity testing that support mechanistic-based risk assessment and for their use as alternatives to animal experimentation. In all instances, adequate quality assurance is necessary to safeguard reproducibility and reliability of results. Validation of cell models has pioneered such quality assurance, but much work still needs to be done to create a culture of evidence-based science.

\section{References}

Aasen, J. A. B., Samdal, I. A., Miles, C. O., et al. (2005). Yessotoxins in Norwegian blue mussels (Mytilus edulis): uptake from Protoceratium reticulatum, metabolism and depuration. Toxicon 45, 265-272.

Aligizaki, K. and Nikolaidis, G. (2006). The presence of the potentially toxic genera Ostreopsis and Coolia (Dinophyceae) in the North Aegean Sea, Greece. Harmful Algae 5, 717-730.

Aligizaki, K., Katikou, P., Nikolaidis, G., and Panou, A. (2008). First episode of shellfish contamination by palytoxin-like compounds from Ostreopsis species (Aegean Sea, Greece). Toxicon 51, 418-427.

Aligizaki, K., Katikou, P., Milandri, A., and Diogène, J. (2011). Occurrence of palytoxin-group toxins in seafood and future strategies to complement the present state of the art. Toxicon 57, 390-399.

Amzil, Z., Pouchus, Y. F., Le Boterff, J., et al. (1992). Short-term cytotoxicity of mussel extracts: A new bioassay for okadaic acid detection. Toxicon 30, 1419-1425.

Aune, T. (1989). Toxicity of marine and freshwater algal biotoxins towards freshly prepared hepatocytes. In S. Natori, K. Hashimoto, and Y. Ueno (eds.), Mycotoxins and Phycotoxins '88 (461-468). Amsterdam, The Netherlands: Elsevier Science Publishers.

Barabasi, A.-L. and Oltvai, Z. N. (2004). Network biology: understanding the cell's functional organization. Nat Rev Genetics 5, 101-113.

Basketter, D. A., Clewell, H., Kimber, I., et al. (2012). A roadmap for the development of alternative (non-animal) methods for systemic toxicity testing $-\mathrm{t}^{4}$ report. ALTEX 29, 3-91. 
Bechinger, B. (1997). Structure and functions of channel-forming peptides: magainins, cecropins, melittin, and alamethicin. J Membr Biol 156, 197-211.

Bellocci, M., Ronzitti, G., Milandri, A., et al. (2008). A cytolytic assay for the measurement of palytoxin based on a cultured monolayer cell line. Anal Biochem 374, 48-55. Addendum in Anal Biochem 380, 178.

Bellocci, M., Sala, G. L., Callegari, F., and Rossini, G. P. (2010). Azaspiracid-1 inhibits endocytosis of plasma membrane proteins in epithelial cells. Toxicol Sci 117, 109-121.

Bellocci, M., Sala, G. L., and Prandi, S. (2011). The cytolytic and cytotoxic activities of palytoxin. Toxicon 57, 449-459.

Biggins, J. B. and Koh, J. T. (2007). Chemical biology of steroid and nuclear hormone receptors. Curr Op Chem Biol 11, 99110 .

Bignami, G. S. (1993). A rapid and sensitive hemolysis neutralization assay for palytoxin. Toxicon 31,817-820.

Boekelheide, K. and Andersen, M. E. (2010). A mechanistic redefinition of adverse effects - a key step in the toxicity testing paradigm shift. ALTEX 27, 243-252.

Boverhof, D. R. and Zacharewski, T. R. (2006). Toxicogenomics in risk assessment: applications and needs. Toxicol Sci 89, 352-360.

Buchanan, M., Caldarelli, G., de los Rios, P., et al. (eds.) (2010). Networks in cell biology. Cambridge, UK: Cambridge University Press.

Butler, D. (2006). Mystery surrounds French oyster ban. http:// www.nature.com/news/2006/060918/full/news060918-8.html

Callegari, F., Ronzitti, G., Ferrari, S., and Rossini, G. P. (2004). Yessotoxins alter the molecular structures of cell-cell adhesion in cultured cells. In K. Henshillwood, B. Deegan, T. McMahon, et al. (eds.), Proceedings of the $5^{\text {th }}$ International Conference on Molluscan Shellfish Safety (407-413). Galway: The Marine Institute.

Callegari, F. and Rossini, G. P. (2008). Yessotoxin inhibits the complete degradation of E-cadherin. Toxicology 244, 133-144.

Cañete, E. and Diogène, J. (2008). Comparative study of the use of neuroblastoma cells (Neuro-2a) and neuroblastoma X glioma hybrid cells (NG108-15) for the toxic effect quantification of marine toxins. Toxicon 52, 541-550.

Castèle, S. and Catterall, W. A. (2000). Molecular mechanisms of neurotoxin action on voltage-gated sodium channels. Biochimie 82, 883-892.

Ciminiello, P., Dell'Aversano, C., Fattorusso, E., et al. (2006). The Genoa 2005 outbreak. Determination of putative palytoxin in Mediterranean Ostreopsis ovata by a new liquid chromatography tandem mass spectrometry method. Anal Chem 78, 6153-6159.

Collins, F. S., Gray, G. M., and Bucher, J. R. (2008). Transforming environmental health protection. Science 319, 906-907.

Costa, L. G. (2006). Current issues in organophosphate toxicology. Clin Chim Acta 366, 1-13.

Crick, F. (1958). On protein synthesis. Symp Soc Exp Biol 12, 138-163.

Crick, F. (1970). Central dogma of molecular biology. Nature $227,561-563$.
Deeds, J. D. and Schwartz, M. (2010). Human risk associated with palytoxin exposure. Toxicon 56, 150-162.

Dell'Aversano, C., Walter, J. A., Burton, I. W., et al. (2008). Isolation and structure elucidation of new and unusual saxitoxin analogues from mussels. J Nat Prod 71, 1518-1523.

Dietrich, D. R. (2010). Courage for simplification and imperfection in the $21^{\text {st }}$ century assessment of "endocrine disruption". ALTEX 27, 264-278.

Durando, P., Ansaldi, F., Oreste, P., et al. (2007). Ostreopsis ovata and human health: epidemiological and clinical features of respiratory syndrome outbreaks from a two year syndromic surveillance, 2005-2006, in north-west Italy. Euro Surveill 12, 191-193.

EC - European Commission (1991). Directive 91/492/EEC. Off $J$ European Communities L268, 1-14.

EC (2002). Decision 2002/225/EC. Off J European Communities L75, 62-64.

EU - European Union (2004). Regulation (EC) No 853/2004. Off J European Union L139, 55-206.

EU (2005). Regulation (EC) No 2074/2005. Off J European Union L338, 27-59.

EU (2011). Regulation (EU) No 15/2011. Off J European Union L6, 3-6.

EFSA (2008). Marine biotoxins in shellfish - Yessotoxin group. EFSA Journal 907, 1-62.

EFSA (2009). Scientific Opinion on marine biotoxins in shellfish - Palytoxin group. EFSA Journal 1393, 1-38.

Fuqua, S. A. W. (ed.) (2009). Hormone receptors in breast cancer. New York, USA: Springer.

Gallacher, S. and Birkbeck, T. H. (1992). A tissue culture assay for direct detection of sodium channel blocking toxins in bacterial culture supernatants. FEMS Microbiol Lett 92, 101-108.

Gallitelli, M., Ungaro, N., Addante, L. M., et al . (2005). Respiratory illness as a reaction to tropical algal blooms occurring in a temperate climate. JAMA 293, 2599-2600.

Hartung, T., Aaberge, I., Berthold, S., et al. (2001). ECVAM workshop on novel pyrogen tests based on the human fever reaction. Altern Lab Anim 29, 99-123.

Hartung, T. (2009). A toxicology for the 21st century: Mapping the road ahead. Toxicol Sci 109, 18-23.

Hartung, T. and McBride, M. (2011). Food for thought ... on mapping the human toxome. ALTEX 28, 83-93.

Hartung, T. and Zurlo, J. (2012). Alternative approaches for medical countermeasures to biological and chemical terrorism and warfare. ALTEX 29, 251-260.

Hartung, T., van Vliet, E., Jaworska, J., et al. (2012). Systems toxicology. ALTEX 29, 119-128.

Hartwell, L. H., Hopfiueld, J. J., Leibler, S., and Murray, A. W. (1999). From molecular to modular cell biology. Nature 402, Suppl., c47-c52.

Hess, P., Grune, B., Anderson, D. B., et al. (2006). Three Rs approaches in marine biotoxin testing. ECVAM Workshop Report 55. Altern Lab Anim 34, 193-224.

Hewitt, S. C., Harrell, J. C., and Korach, K. S. (2005). Lessons in estrogen biology from knockout and transgenic animals. Annu Rev Physiol 67, 285-308. 
Hoffmann, S., Peterbauer, A., Schindler, S., et al. (2005). International validation of novel pyrogen tests based on the human fever reaction. J Immunol Meth 298, 161-173.

Hotchkiss, A. K., Rider, C. V., Blystone, C. R., et al. (2008). Fifteen years after "Wingspread" - Environmental endocrine disrupters and human and wildlife health: Where we are today and where we need to go. Toxicol Sci 105, 235-259.

Hu, T. M., Curtis, J. M., Oshima, Y., et al. (1995). Spirolide-B and spirolide-D, 2 novel macrocycles isolated from the digestive glands of shellfish. J Chem Soc Chem Commun 20, 21592161.

Inglese, J., Auld, D. S., Jadhav, A., et al. (2006). Quantitative high-throughput screening: A titration-based approach that efficiently identifies biological activities in large chemical libraries. Proc Natl Acad Sci USA 103, 11473-11478.

Judson, R., Elloumi, F., Setzer, R. W., et al. (2008). A comparison of machine learning algorithms for chemical toxicity classification using a simulated multi-scale data model. BMC Bioinformatics 9, 241.

Jellett, J. F., Marks, L. J., Stewart, J. E., et al. (1992). Paralytic shellfish poison (saxitoxin family) bioassay: Automated endpoint determination and standardization of the in vitro tissue culture bioassay, and comparison with the standard mouse bioassay. Toxicon 30, 1143-1156.

Jensen, E. V. and Jacobson, H. I. (1962). Basic guides to the mechanism of estrogen action. Recent Progr Horm Res 18, 387-414

Kholodenko, B. N. (2006). Cell-signalling dynamics in time and space. Nat Rev Mol Cell Biol 7, 165-176.

King, R. A., Rotter, J. I., and Motulsky, A. G. (2002) (eds.). The genetic basis of common diseases. New York, Oxford: University Press.

Kirkland, D., Aardema, M., Henderson, L., and Müller, L. (2005). Evaluation of the ability of a battery of three in vitro genotoxicity tests to discriminate rodent carcinogens and noncarcinogens. Mutat Res 584, 1-256.

Klein-Hitpass, L., Ryffel, G. U., Heitling, E., and Cato, A. C. B. (1988). A 13 bp palindrome is a functional estrogen responsive element and interacts specifically with estrogen receptor. Nucl Ac Res 16, 647-663.

Kogure, K., Tamplin, M. L., Simidu, U., and Colwell, R. R. (1988). A tissue culture assay for tetrodotoxin, saxitoxin and related toxins. Toxicon 26, 191-197.

Kortenkamp, A., Martin, O., Faust, M., et al. (2011). State of the art assessment of endocrine disrupters. Final Report, 23.12.2011. http://ec.europa.eu/environment/endocrine/documents/4_SOTA\%20EDC\%20Final\%20Report\%20V3\%20 6\%20Feb\%2012.pdf

Krewski, D., Westphal, M., Al-Zoughool, M., et al. (2011). New directions in toxicity testing. Annu Rev Public Health 32, 161178.

Lakatos, I. (1978). The methodology of scientific research programmes. Cambridge: Cambridge University Press.

Ledreux, A., Sérandour, A.-L., Morin, B., et al. (2012). Collaborative study for the detection of toxic compounds in shellfish extracts using cell-based assays. Part II: application to shell- fish extracts spiked with lipophilic marine toxins. Anal Bioanal Chem 403, 1995-2007.

Lettieri, T. (2006). Recent applications of DNA microarray technology to toxicology and ecotoxicology. Env Health Persp $114,4-9$.

Lonard, D. M. and O'Malley, B. W. (2006). The expanding cosmos of nuclear receptor coactivators. Cell 125, 411-414.

MacKenzie, A. L., Holland, P. T., McNabb, P., et al. (2002). Complex toxin profiles in phytoplankton and Greenshell mussels (Perna canaliculus), revealed by LC-MS/MS analysis. Toxicon 40, 1321-1330.

Mangelsdorf, D. J., Thummel, C., Beato, M., et al. (1995). The nuclear receptor superfamily: the second decade. Cell 83,835 839.

Manger, R. L., Leja, L. S., Lee, S. Y., et al. (1993). Tetrazoliumbased cell bioassay for neurotoxins active on voltage-sensitive sodium channels: semiautomated assay for saxitoxins, brevetoxins, and ciguatoxins. Anal Biochem 214, 190-194.

McKenna, N. J. and O'Malley, B. W. (2000). An issue of tissues: divining the split personalities of selective estrogen receptor modulators. Nat Med 6, 960-962.

Moore, R. E. and Scheuer, P. J. (1971). Palytoxin: a new marine toxin from a Coelenterate. Science 172, 495-498.

Naciff, J. M. and Daston, G. P. (2004). Toxicogenomic approach to endocrine disrupters: Identification of transcript profile characteristic of chemicals with estrogenic activity. Toxicol Pathol 32, Suppl. 2, 59-70.

Natarajan, M., Lin, K.-M., Hsueh, R. C., et al. (2006). A global analysis of cross-tals in a mammalian cellular signalling network. Nat Cell Biol 8, 571-580.

Norman, A. W., Mizwiki, M. T., and Norman, D. P. G. (2004). Steroid-hormone rapid actions, membrane receptors and a conformational ensemble model. Nat Rev Drug Discov 3, 27-41.

NRC - National Research Council (2007). Toxicity Testing for the $21^{\text {st }}$ Century: A Vision and a Strategy. Washington D.C., USA: National Academies Press.

O'Malley, B. W. and McGuire, W. L. (1968). Studies on the mechanism of estrogen-mediated tissue differentiation: regulation of nuclear transcription and induction of new RNA species. Proc Natl Acad Sci USA 60, 1527-1534.

Papin, J. A., Hunter, T., Palsson, B. O., and Subramaniam, S. (2005). Reconstruction of cellular signaling networks and analysis of their properties. Nat Rev Mol Cell Biol 6, 99-111.

Patent Application (2002). Process for the measurement of dinophysistoxin and of yessotoxin. International Publication Number: WO 02/03060; Applicant: Università degli Studi di Modena e Reggio Emilia; Inventor: Gian Paolo Rossini. PCT Gazette, Publication date: January 10, 2002; priority date: June 30, 2000.

Penna, A., Vila, M., Fraga, S., et al. (2005). Characterization of Ostreopsis and Coolia (Dinophyceae) isolates in the Western Mediterranean Sea based on morphology, toxicity and internal transcribed spacer 5.8S rDNA sequences. J Phycol 41, 212-225.

Pierotti, S., Malaguti, C., Milandri, A., et al. (2003). Functional assay to measure yessotoxins in contaminated mussel samples. Anal Biochem 312, 208-216. 
Rehmann, N., Hess, P., and Quilliam, M. A. (2008). Discovery of new analogs of the marine biotoxin azaspiracid in blue mussels (Mytilus edulis) by ultra performance liquid chromatography-tandem mass spectrometry. Rapid Commun Mass Spectrom 22, 549-558.

Rhomberg, L. R., Goodman, J. E., Foster, W. G., et al. (2012). A critique of the European Commission Document, "State of the Art Assessment of Endocrine Disrupters." Critic Rev Toxicol 42, 465-473.

Riobó, P., Paz, B., Franco, J.M., et al. (2008). Proposal for a simple and sensitive haemolytic assay for palytoxin. Toxicological dynamics, kinetics, ouabain inhibition and thermal stability. Harmful Algae 7, 415-429.

Riobó, P. and Franco, J. M. (2011). Palytoxins, Biological and chemical deternmination. Toxicon 57, 368-375.

Rockel, C. and Hartung, T. (2012). Systematic review of membrane components of Gram-positive bacteria responsible as pyrogens for inducing human monocyte/macrophage cytokine release. Front Pharmacol 3, doi:10.3389/fphar.2012.00056. http://www.frontiersin.org/Predictive_Toxicity/10.3389/ fphar.2012.00056/abstract

Ronzitti, G., Hess, P., Rehmann, N., and Rossini, G. P. (2007). Azaspiracid-1 alters the E-cadherin pool in epithelial cells. Toxicol Sci 95, 427-435.

Rossini, G. P. (2005). Functional assays in marine biotoxin detection. Toxicology 207, 451-462.

Rossini, G. P. and Hess, P. (2010). Phycotoxins: chemistry, mechanisms of action and shellfish poisoning. In A. Luch (ed.), Molecular, Clinical and Environmental Toxicology (65122). Basel, Switzerland: Birkhäuser-Verlag AG.

Rossini, G. P. and Bigiani, A. (2011). Palytoxin action on the $\mathrm{Na}^{+}, \mathrm{K}^{+}$-ATPase and the disruption of ion equilibria in biological systems. Toxicon 57, 429-439.

Rossini, G. P., Sala, G. L., Ronzitti, G., and Bellocci, M. (2011). The use of proteomics in the study of molecular responses and toxicity pathways in biological systems. In J. C. Fishbein (ed.), Advances in Molecular Toxicology. Vol. 5 (45-109). Amsterdam, The Netherlands: Elsevier.

Rüegg, J., Swedenborg, E., Wahlström, D., et al. (2008). The transcription factor Aryl Hydrocarbon receptor nuclear translocator functions as an estrogen receptor $\beta$-selective coactivator, and its recruitment to alternative pathways mediates antiestrogenic effects of dioxin. Mol Endocrinol 22, 304-316.

Safe, S. H., Pallaroni, L., Yoon, K., et al. (2002). Problems for risk assessment of endocrine-active estrogenic compounds. Env Health Persp 110, 925-929.

Safe, S. and Wormke, M. (2003). Inhibitory aryl hydrocarbon receptor-estrogen receptor $\alpha$ cross-talk and mechanisms of action. Chem Res Toxicol 16, 807-816.

Schindler, S., Spreitzer, I., Loschner, B., et al. (2006). International validation of pyrogen tests based on cryopreserved human primary blood cells. J Immunol Meth 316, $42-51$.
Schindler, S., von Aulock, S., Daneshian, M., and Hartung, T. (2009). Development, validation and applications of the monocyte activation test for pyrogens based on human whole blood. ALTEX 26, 293-305.

Shanle, E. K. and Xu, W. (2011). Endocrine disrupting chemicals targeting estrogen receptor signaling: identification and mechanism of action. Chem Res Toxicol 24, 6-19.

Shiau, A. K., Barstad, D., Loria, P. M., et al. (1998). The structural basis of estrogen receptor/coactivator recognition and the antagonism of this interaction by tamoxifen. Cell 95, 927937.

Tichadou, L., Glaizal, M., Armengaud, A., et al. (2010). Health impact of unicellular algae of the Ostreopsis genus blooms in the Mediterranean Sea: experience of the French Mediterranean coast surveillance network from 2006 to 2009. Clin Toxicol 48, 839-844.

Tubaro, A., Durando, P., Del Favero, G., et al. (2011). Case definition for human poisoning postulated to palytoxin exposure. Toxicon 57, 478-495.

Usami, M., Satake, M., Ispida, S., et al. (1995). Palytoxin analogs from the dinoflagellate Ostreopsis siamensis. J Am Chem Soc 117, 5389-5390.

van Vliet, E. (2011). Current standing and future prospects for the technologies proposed to transform toxicity testing in the $21^{\text {st }}$ century. ALTEX 28, 17-44.

Wehling, M. and Lösel, R. (2006). Non-genomic steroid hormone effects: membrane or intracellular receptors? J Steroid Biochem Mol Biol 102, 180-183.

Weinberg, R. A. (2006). The biology of cancer. New York, USA: Taylor \& Francis.

Zuang, V., Eskes, C., Griesinger, C., and Hartung, T. (2008). ECVAM key area topical toxicity: update on activities. ALTEX 14, S523-S528.

\section{Acknowledgements}

The valuable discussions with the ECVAM taskforces for endocrine disruption and shellfish toxin testing, and especially with Dan Dietrich, Konstanz, are gratefully appreciated by T. H. A CAAT $\mathrm{t} 4$ workshop on shellfish toxin testing was held in 2010 and its report is currently being finalized.

\section{Correspondence to}

Gian Paolo Rossini, DSc

Dipartimento di Scienze della Vita

Università di Modena e Reggio Emilia

Via G. Campi 287

41125 Modena

Italy

e-mail: gianpaolo.rossini@unimore.it 